\title{
A new species of Umanella Gauld (Hymenoptera, Ichneumonidae) from Ecuador
}

\author{
Gavin R. Broad ${ }^{1, \dagger}$, Ilari E. Sääksjärvini, ${ }^{2, \ddagger}$ Edgard Palacio ${ }^{3, \S}$ \\ Nacional de Colombia \\ † urn:lsid:zoobank.org:author:D06689DE-526F-4CFA-8BEB-9FB38850754A \\ † urn:lsid:zoobank.org:author:2B80E7A4-FEA6-4493-80C1-5B28FBOCDB8F \\ § urn:lsid:zoobank.org:author:4D5CFDF5-0143-4119-81D3-18A29915EEAF \\ Corresponding author: Gavin R. Broad (g.broad@nhm.ac.uk)
}

I Department of Entomology, the Natural History Museum, Cromwell Road, London SW7 5BD, UK 2 Zoological Museum, Section of Biodiversity and Environmental Sciences, Department of Biology, FIN-20014 University of Turku, Finland 3 Laboratorio de Artrópodos - Grupo de Biotecnologia - CIF, Universidad

Academic editor: Michael Sharkey| Received 13 November 2009 | Accepted 29 January 2010 | Published 2 February 2010

urn:lsid:zoobank.org:pub:964540F2-C9F8-413B-B1C2-56A8A2761B82

Citation: Broad GR, Sääksjärvi IE, Palacio P (2010) A new species of Umanella Gauld (Hymenoptera, Ichneumonidae) from Ecuador. ZooKeys 35: 77-90. doi: 10.3897/zookeys.35.326

\begin{abstract}
Recently collected specimens of the distinctive pimpline genus, Umanella, from Colombia and Ecuador are assigned to Umanella caerulea Gauld (now known from Costa Rica and Colombia) and Umanella giacometti Broad \& Sääksjärvi, sp. n. (from Ecuador). Variation within and between species is evaluated.
\end{abstract}

\section{Keywords}

Taxonomy, Pimplinae, Amazonia

\section{Introduction}

South America is home to several large, metallic ichneumonids, mostly in the subfamily Cryptinae. Within the subfamily Pimplinae, metallic blue pimplines were known in the genus Pimpla, then Ian Gauld described a large, distinctive, metallic blue pim- 
pline from Costa Rica as a new genus and species, Umanella caerulea (Gauld, 1991). Since then, several more specimens of Umanella have been collected in Colombia and Ecuador but no other specimens are known from older collections. As Umanella are large and likely to attract attention there are probably not many undescribed species. Here we evaluate the variation between specimens and describe those from Ecuador as a second species, Umanella giacometti Broad \& Sääksjärviq sp. n.

\section{Materials and methods}

Specimen depositories are abbreviated as follows:

BMNH Natural History Museum, London

NMNH National Musuem of Natural History, Washington

ZMUT Zoological Museum, University of Turku, Finland

IAVH Entomological collection, Instituto Alexander von Humboldt, Villa de Leyva, Colombia

Most images of specimens in BMNH were taken with a Canon EOS 450D digital camera attached to a Zeiss Stemi SV11 stereomicroscope. Several partially focused images were combined using Helicon Focus v. 4.80 software. Layer photos of one male paratype (USNM / ZMUT) were taken with an Olympus SZX16 stereomicroscope attached to an Olympus E520 digital camera. Images were combined using the programmes Deep Focus 3.1 and Quick PHOTO CAMERA 2.3. Morphological terminology follows Gauld (1991). Fore wing length is given from the hind edge of the tegula to the apex of the wing. Ovipositor length is measured from the base of the ovipositor, i.e. anterior to the end of the metasoma.

\section{Taxonomy}

The specimen base for this study is small as Umanella are rarely collected and apparently sparsely distributed. 'We have examined a total of 21 specimens, 12 from Costa Rica (10 females, two males) (BMNH, IAVH), four from Colombia (two females, two males) (BMNH, IAVH) and five from Ecuador (two females, three males) (BMNH, USNM and ZMUT). Female specimens of $U$. caerulea predominate.

Although specimens from Ecuador are noticeably larger than those from Costa Rica and Colombia there are no discrete morphological differences between these populations. Umanella specimens lack most carinae, the integument being mostly unsculptured and metallic-looking. The only structural differences we could find between females were (1) the shape of the sides of the swelling on the second tergite, and (2) overall size and the relative length of the ovipositor, as compared to fore wing length. In addition, there are distinct colour differences, concerning (3) the presence or absence of a violet tinge on the metasoma, (4) the colour pattern of the mid tibia and, 
Table I. Comparison of ten characters between Umanella specimens.

\begin{tabular}{|c|c|c|c|c|c|}
\hline Costa Rica & $\begin{array}{l}\text { Colombia } \\
\text { (NHM) }+9\end{array}$ & $\begin{array}{l}\text { Colombia } \\
\text { (IAVH) }+9 \\
\end{array}$ & $\begin{array}{l}\text { Colombia } \\
(\text { IAVH52644) }\end{array}$ & $\begin{array}{l}\text { Colombia } \\
\text { (IAVH52646) } \widehat{\partial}\end{array}$ & Ecuador \\
\hline $\begin{array}{l}\text { Female maxillary } \\
\text { palps with white } \\
\text { segments }\end{array}$ & $\begin{array}{l}\text { with white } \\
\text { segments }\end{array}$ & $\begin{array}{l}\text { with brown } \\
\text { segments }\end{array}$ & $\begin{array}{l}\text { with white } \\
\text { segments }\end{array}$ & $\begin{array}{l}\text { with white } \\
\text { segments }\end{array}$ & brown \\
\hline $\begin{array}{l}\text { Female fore } \\
\text { trochanter with } \\
\text { cream/white } \\
\text { streak }\end{array}$ & $\begin{array}{l}\text { with cream/ } \\
\text { white streak }\end{array}$ & $\begin{array}{l}\text { with cream/ } \\
\text { white streak }\end{array}$ & $\begin{array}{l}\text { with cream/white } \\
\text { streak }\end{array}$ & $\begin{array}{l}\text { with cream/white } \\
\text { streak }\end{array}$ & $\begin{array}{l}\text { lacking streak, } \\
\text { narrowly } \\
\text { white at apex }\end{array}$ \\
\hline $\begin{array}{l}\text { Male tegula } \\
\text { brown }\end{array}$ & - & - & metallic blue & brown & $\begin{array}{l}\text { whitish- } \\
\text { transparent }\end{array}$ \\
\hline $\begin{array}{l}\text { Male mid coxa } \\
\text { predominantly } \\
\text { white }\end{array}$ & - & - & $\begin{array}{l}\text { brown with } \\
\text { metallic blue } \\
\text { tinges }\end{array}$ & mainly brown & white \\
\hline $\begin{array}{l}\text { Male mid femur } \\
\text { with hind side } \\
\text { brown, distally } \\
\text { brown }\end{array}$ & - & - & hind side brown & hind side brown & $\begin{array}{l}\text { only distally } \\
\text { brown }\end{array}$ \\
\hline $\begin{array}{l}\text { Mid tibia with } \\
\text { yellowish apex, } \\
\text { not abruptly } \\
\text { differentiated }\end{array}$ & $\begin{array}{l}\text { yellowish } \\
\text { apex, not } \\
\text { abruptly } \\
\text { differentiated }\end{array}$ & $\begin{array}{l}\text { almost } \\
\text { entirely } \\
\text { white }\end{array}$ & $\begin{array}{l}\text { yellowish apex, } \\
\text { not abruptly } \\
\text { differentiated }\end{array}$ & $\begin{array}{l}\text { yellowish apex, } \\
\text { not abruptly } \\
\text { differentiated }\end{array}$ & $\begin{array}{l}\text { apex abruptly } \\
\text { differentiated, } \\
\text { white, or } \\
\text { entirely white }\end{array}$ \\
\hline $\begin{array}{l}\text { Male first tergite } \\
\text { broader, c. } 2.2 \times \\
\text { as long as broad }\end{array}$ & - & - & $\begin{array}{l}\text { slenderer, c. } 4.0 \times \\
\text { as long as broad }\end{array}$ & $\begin{array}{l}\text { slenderer, c. } 3.6 \times \\
\text { as long as broad }\end{array}$ & $\begin{array}{l}\text { slenderer, c. } \\
3.7-5.0 \times \text { as } \\
\text { long as broad }\end{array}$ \\
\hline $\begin{array}{l}\text { Second tergite } \\
\text { with sides of } \\
\text { median swelling } \\
\text { slightly convex }\end{array}$ & convex & $\begin{array}{l}\text { slightly } \\
\text { convex }\end{array}$ & slightly convex & slightly convex & concave \\
\hline $\begin{array}{l}\text { Metasoma blue } \\
\text { with purple tinge }\end{array}$ & $\begin{array}{l}\text { blue with } \\
\text { purple and } \\
\text { brown tinges }\end{array}$ & $\begin{array}{l}\text { blue, with } \\
\text { purple } \\
\text { and brown } \\
\text { tinges }\end{array}$ & $\begin{array}{l}\text { blue, with purple } \\
\text { and brown tinges }\end{array}$ & $\begin{array}{l}\text { brown, with } \\
\text { purple tinges }\end{array}$ & $\begin{array}{l}\text { blue or brown } \\
\text { with blueish } \\
\text { tinges }\end{array}$ \\
\hline $\begin{array}{l}\text { Ovipositor of } \\
\text { large specimens } \\
\text { relatively long, } \\
\text { c. } 2.8 \times \text { fore } \\
\text { wing, of small } \\
\text { specimens } \\
\text { relatively short, c. } \\
2 \times \text { fore wing } \\
\end{array}$ & $\begin{array}{l}\text { c. } 2.8 \times \text { fore } \\
\text { wing }\end{array}$ & $\begin{array}{l}\text { c. } 1.6 \times \text { fore } \\
\text { wing }\end{array}$ & - & - & $\begin{array}{l}\text { c. } 2.2 \times \text { fore } \\
\text { wing }\end{array}$ \\
\hline
\end{tabular}

(5) in the amount of white on the fore trochanter (see Table 1). The few known males offer some small differences between populations: the colour pattern of the mid femur and tegula differs between those from Ecuador and those from Costa Rica / Colombia. It seems that the single paratype of $U$. caerulea in BMNH is anomalously small and has a much broader first tergite than the other males examined. Smaller specimens of both sexes are distinctly brown on the metasoma. Table 1 describes the characters that 
vary between specimens from Costa Rica, Colombia and Ecuador: we consider variation between Colombian and Costa Rican specimens to be minor, whereas there are distinct differences in several characters when comparing these specimens with those from Ecuador. Therefore we are describing the Ecuadorean specimens as a new species.

\section{Umanella Gauld, 1991}

Gauld (1991) provides an excellent description of the genus Umanella, which we are not repeating here, and provides a key to Costa Rican Pimplinae genera which serves to diagnose Umanella anywhere in South America. Of the South American Pimplinae, Umanella is the only genus with a long ovipositor, metallic blue colouration (Fig. 1) and lacking the epicnemial carina (Fig. 2). Some Pimpla are metallic blue but can be easily separated by the relatively short ovipositor (less than half as long as fore wing), generally stout body and presence of the epicnemial carina. Some Neotropical Dolichomitus resemble Umanella in body shape but are never metallic blue in colouration and lack the lateral denticles on the apex of the upper valve of the ovipositor.

\section{Umanella caerulea Gauld, 1991}

Description. See Gauld (1991). Essentially similar to U. giacometti but differing in the characters listed in Table 1. Only characters that are useful in differentiating $U$. caerulea from U. giacometti are emphasised here, although complete descriptions of female and male colour patterns are given.

Female. Fore wing length $12-15 \mathrm{~mm}$. Ovipositor length $23-43 \mathrm{~mm}$, ratio of ovipositor to fore wing (1.60) 1.92-2.87 ( $\mathrm{n}=10)$; smaller specimens with relatively shorter ovipositor, larger specimens with relatively longer ovipositor (but with one exception, see variation). First tergite of metasoma 3.4-3.7 $\times$ as long as apically wide, second tergite 2.1-2.6 $\times$ as long as apically wide. Second tergite with narrow, drop-shaped median area defined, sides of raised area slightly convex (Fig. 3A, B).

Colour: metallic blue, duller towards apex of metasoma, fading to dark brown. Metasoma with purple tinge, sometimes strongly so. Ground colour of metasoma brown. Female from Colombia $(\mathrm{BMNH})$ with metasoma largely brown, but with some blue and purple gloss. Antennae black, except for white, sub-apical annulus on five to seven flagellomeres. Maxillary palps dark brown basally and apically, dull white on third and fourth segments.'Tegula centrally metallic blue, brown around edges. Wing venation, including stigma, dark brown. Wing membrane slightly infuscate basally, distinctly infuscate in apical quarter. Legs with coxae, trochanters and trochantelli shiny, metallic (dark) blue. Fore leg with large apical patch on trochanter (or entire front side) creamy white, extreme apex of trochantellus brown, conspicuous creamy streak along front edge of femur (from apical half to entire length); fore tibia with basal 0.6 brown (slightly paler sub-basally); fore tarsus brown fading to yellowish on third and fourth tarsomeres, fifth tarsomere black. Mid femur with tiny basal patch to 
conspicuous basal streak creamy; mid tibia brown with dull yellowish mark sub-basally and fading to yellowish on apical quarter (black at extreme apex) (Fig. 4A, B) or almost entirely white (black very apically (Fig. 4C). Legs otherwise marked as in U. giacometti but pale markings are duller, usually more yellow.

Paratype male (BMNH). Whole insect: Fig. 6. Fore wing length $7.5 \mathrm{~mm}$, body length (from antennal insertion to apex of genitalia) $7.8 \mathrm{~mm}$. Submetapleural carina complete. First metasomal tergite $2.2 \times$ as long as maximum width (Fig. 5A), second tergite $1.6 \mathrm{x}$ as long as wide. Second and third tergites with strong diagonal, basal grooves cutting off raised, central section which is raised posteriorly. First and second tergites with strong setae laterally, first tergite and basal half of second smooth dorsally, metasoma setose dorsally from second half of second tergite. Sclerotized part of first tergite extending to 0.2 of distance between spiracle and hind edge. Some dorsal punctures on apical half of second tergite, following tergites regularly punctate and setose dorsally.

Colour: head and mesosoma metallic blue. Antennae black, white on 7 (22nd to 28th) flagellomeres. Maxillary and labial palps white. Tegula brown. Wing venation, including stigma, dark brown. Wing membrane clear basally, slightly infuscate in apical quarter. Fore leg white on fore side, except apical tarsomere brown. Hind side of fore leg basally white, trochantellus and femur brown; fore tibia pale brown over basal quarter, apex narrowly dark brown; fore tarsus pale brown except apical tarsomere dark brown. Mid leg with coxa and trochanter white, trochantellus brown, fore side of femur brown on basal 0.15 , remainder white, fore side of mid tibia vaguely infuscate brown basally and medially, dark brown at very apex, hind side of femur brown, hind side of tibia brown over basal 0.6 , slightly paler patch sub-basally, mid tarsus dark brown on first, second and fifth tarsomeres, third and fourth white. Hind leg with metallic blue coxa, metallic darker blue on trochanter and trochantellus, turning to black on femur; apex of hind trochantellus and base of femur narrowly brown; hind tibia black with narrow annulus sub-basally, white on outer side, brown on inner side; hind tarsus dark brown on first, basal 0.7 of second and apical 0.5 of fifth tarsomeres, remainder white. Metasoma with first tergite metallic blue, second and third tergites brown with dark brown apical rims, remaining tergites dark brown; first sternite with sclerotized part metallic blue, sclerotized sections of other sternites brown, membranous parts of sternites white.

Variation. 'The single male in BMNH seems to be unusually small and stout, compared to male specimens from Colombia in IAVH and has deformed antennae (Fig. 7). One male in IAVH has the metasoma almost entirely metallic blue. There is variation in the amount of white on the mid tibia of females (Fig. 4A, B, C), in the amount of metallic blue colouration on the metasoma and in the relative length of the ovipositor (Table 1). Much of this variation we assume is size-related (smaller specimens seem to be more extensively white and brown), but one female specimen from Colombia in IAVH is particularly stout, with length to breadth ratios of the 1st and 2nd tergites of 3.4 and 2.1, respectively, and the ovipositor only $1.6 \mathrm{x}$ the length of the fore wing (which is relatively large, at $14 \mathrm{~mm}$ ). The mid tibia of this specimen is almost entirely white. Whether this specimen represents a third species or is just at the 
extreme end of variation within U. caerulea we are unable to say at present but it would be desirable to see more Umanella specimens from Colombia.

Biology. Nothing is known.

Distribution. Known from from Costa Rica (see Gauld, 1991, Gauld et al., 1998), and now from Colombia: female, Amazonas, PNN Amacayacu, 150m, Malaise trap, 15.X.2001-5.XI.2001, 03ㄴ' ${ }^{\circ}$ S, 70 ${ }^{\circ} 18^{\prime} \mathrm{W}$, D. Chota (IAVH); female, Narińo, Barbacoas, 40 m, 28.X.1990, M. Cooper (BMNH); male, Chocó, PNN Utría, 10m, Malaise trap, 1.VII.2000-5.VII.2000, $06^{\circ} 01^{\prime} \mathrm{N}, 77^{\circ} 20^{\prime} \mathrm{W}, \mathrm{B}$. Brown (IAVH); male, Valle, PNN Los Farallones, 650m, Malaise trap, 1.VIII.2000-10.IX.2000, $03^{\circ} 26^{\prime} \mathrm{N}$, $76^{\circ} 48^{\prime} \mathrm{W}$, S. Sarria (IAVH).

\section{Umanella giacometti Broad \& Sääksjärvi, sp. n.}

urn:lsid:zoobank.org:act:A0FF698D-9560-4401-BDC9-13529E6460A8

Description. Female. Whole insect: Fig. 1. 'Fore wing length 18.5 (holotype)-20 $\mathrm{mm}$, body length (from antennal insertion to apex of metasoma) $31-34 \mathrm{~mm}$, ovipositor length 41 (holotype) $-45 \mathrm{~mm}$, ratio of ovipositor to fore wing length 2.22 2.25. Occipital carina complete, joining hypostomal carina behind base of mandible, dipped mediodorsally with depression on vertex and deep groove on back of head. Epomia present for short distance across trough in pronotum. Notauli deep and long, converging but not meeting posteriorly, petering out at about half the length of mesoscutum. Epicnemial carina absent (Fig. 2). Mesopleurum with posterior suture weakly impressed dorsally, strong ventrally, smooth except for some weak crenulae, and deeply impressed furrow connnecting suture to episternal scrobe. Mesepisternal sulcus complete, strong and non-crentulate. Posterior transverse carina of mesosternum absent. Propodeum lacking all carinae except pleural and submetapleural carinae, which are complete, and stubs of median longitudinal carinae, present at posterior end of propodeum. Faint, narrow groove present on dorsal, ventral half of propodeum. Propodeal spiracle about twice as long as medially wide. Whole body elongate and integument entirely smooth and shining except mandible sparsely punctate basally, puncto-striate medially. Upper tooth of mandible slightly shorter than lower tooth. Hind coxa about 1.2 as long as dorsal face of propodeum. First tergite of metasoma $4.4 \times$ as long as apically wide, second tergite $2.8 \times$ as long as apically wide. First tergite with swollen, apical area, posterior end impressed behind it. Sclerotized part of first sternite with low, raised bump just before level of spiracle; extends to half distance between spiracle and posterior end of tergite. Second tergite with deep, diagonal grooves cutting off anterior corners; narrow, drop-shaped median area defined, sides of raised area concave (Fig. 3C). Third and fourth tergites with deep, lateral grooves. Metasoma with strong setae laterally. All tarsal claws with acute basal lobe. Fore tibia with longitudinal patch of stronger, darker setae. Propodeum with coxal foramen narrowly separated from metasomal foramen by sclerotized bridge. Ovipositor with tip angled downwards. Lower valve of ovipositor apically slightly overlapping 


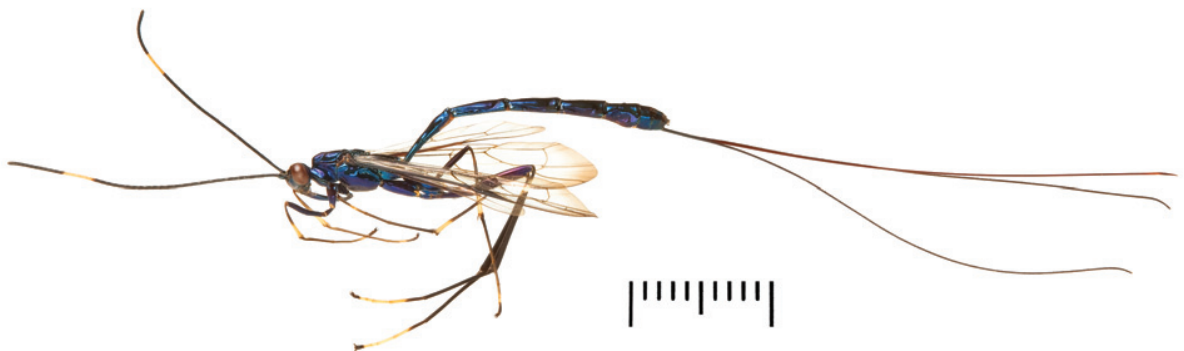

Figure I. Umanella giacometti, female holotype; scale bar $=10 \mathrm{~mm}$.

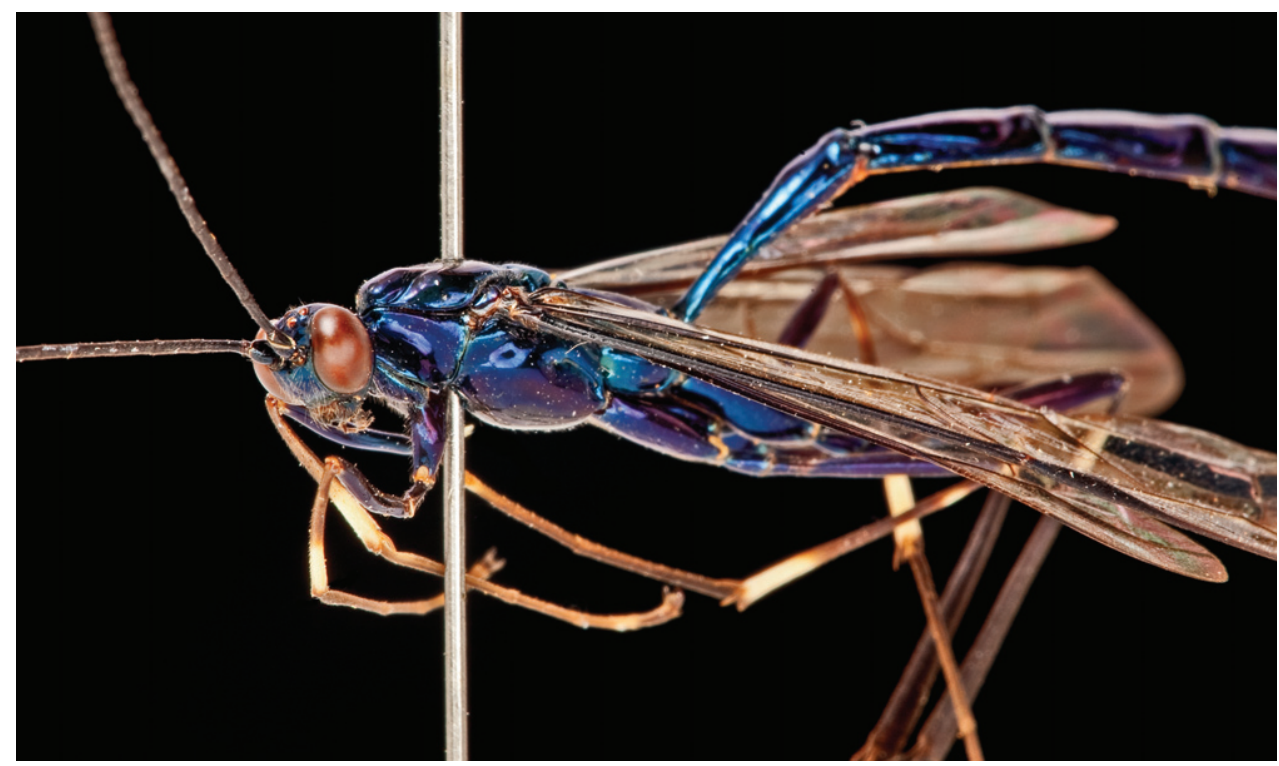

Figure 2. $U$. giacometti, female holotype, detail of head and mesosoma.

dorsal valve, with 13 visible teeth, regularly spaced and inclined. Dorsal valve with row of lateral denticles above teeth on each side.

Colour: metallic blue, duller towards apex of metasoma. Antennae black, except for white, sub-apical annulus on three and a half flagellomeres (23rd to 26th) to five (holotype, 23rd to 27th) flagellomeres. Maxillary palps dark brown, a little paler centrally, ventrally. Tegula metallic blue. Wing venation, including stigma, dark brown. Wing membrane slightly infuscate basally (holotype) or distinctly brown, distinctly infuscate in apical quarter. Legs with coxae, trochanters and trochantelli shiny, metallic (dark) blue. Fore leg with apical edge of trochanter creamy white with white streak extending over basal half of anterior surface of fore femur, extreme apex of trochantellus and base of femur brown; fore tibia with basal 0.6 brown (slightly paler sub-basally); fore tarsus brown except apical half of third and fourth tarsomeres creamy, fifth tarsomere black. Mid tibia black with small, dull creamy mark sub-basally and abruptly 


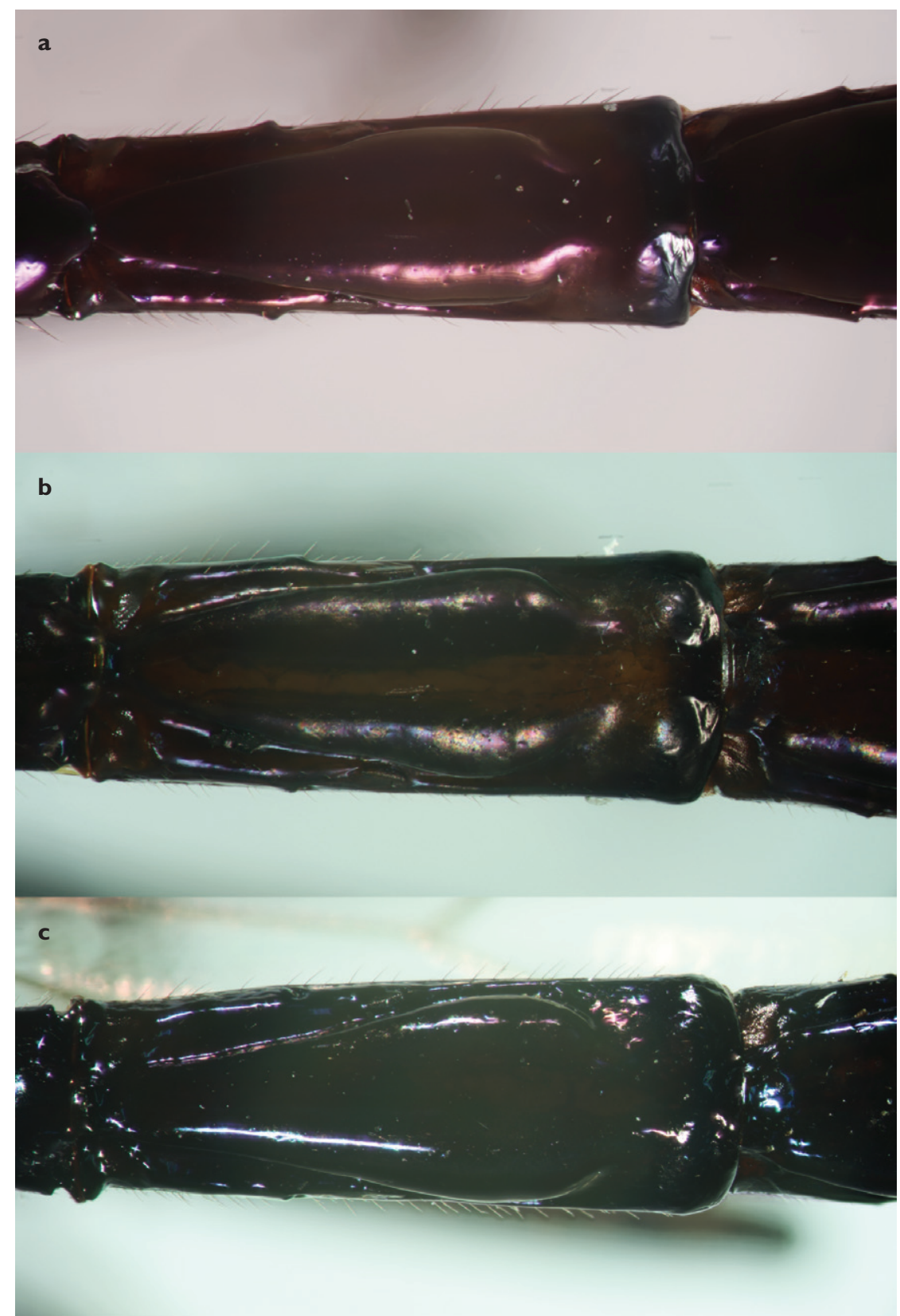

Figure 3. Second tergite of female metasoma of a U. caerulea from Costa Rica b U. caerulea from Colombia c $U$. giacometti; anterior to the right.

white on apical quarter (black at extreme apex) (Fig. 4D); mid tarsus brown to black, except fourth and apical half of third tarsomere creamy. Hind tibia with white annulus sub-basally; hind tarsus black on first, basal half of second and apical half of fifth tarsomeres, remainder creamy. 


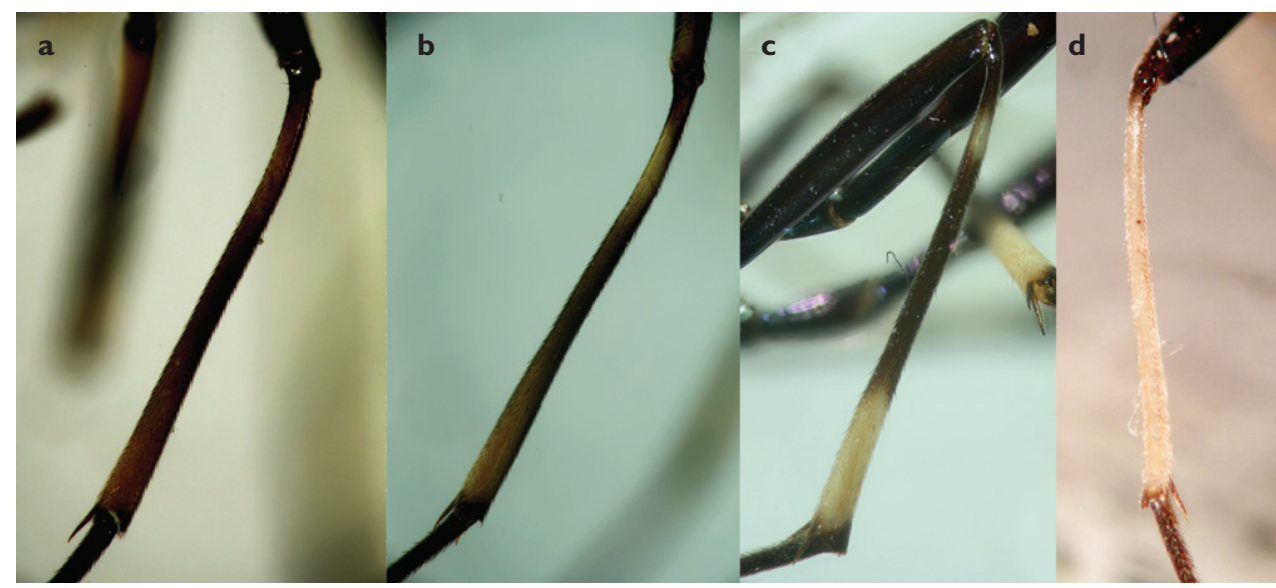

Figure 4. Mid tibia of $\mathbf{a}$ female of $U$. caerulea from Costa Rica $\mathbf{b}$ female of $U$. caerulea from Colombia $(\mathrm{BMNH}) \mathbf{c}$ female of $U$. caerulea from Colombia (IAVH) $\mathbf{d}$ female of $U$. giacometti.

Paratype males. Whole insect: Figs 8, 9. Fore wing length 10-14 mm, body length (from antennal insertion to apex of genitalia) 15-21 mm. Submetapleural carina complete to about two thirds length of propodeum then abruptly weaker (barely traceable on smaller specimen) for remainder. First metasomal tergite 3.7 to $4.0 \times$ as long as maximum width (Fig. 5B), second tergite 2.7 to $3.1 \times$ as long as wide. Second and third tergites with strong diagonal, basal grooves cutting off raised, central section which is raised posteriorly (Fig. 10). First and second tergites with strong setae laterally but smooth dorsally. Sclerotized part of first tergite extending to 0.5 of distance between spiracle and hind edge. Third tergite regularly punctate and setose dorsally. Fourth tergite onwards setose dorsally with inconspicuous punctures.

Colour: head and mesosoma metallic blue. Antennae dark brown to black, white on 3-11 (22nd to 32nd) flagellomeres. Maxillary and labial palps cream coloured. Tegula white-transparent. Wing venation, including stigma, dark brown. Wing membrane clear basally, infuscate in apical quarter. Fore leg white on fore side, except apical tarsomere black or dark brown, other tarsomeres off white, basal half of first tarsomere pale brown to white. Hind side of fore leg basally white, but coxa with slight brown hint, femur with broad ventral streak on apical 0.7 , light or dark brown fading into metallic blue; fore tibia brown on basal half, apex narrowly dark brown. Mid leg with coxa and trochanter white, trochantellus dark brown to black, fore side of femur dark brown to black on basal 0.15 , remainder white; mid tibia almost totally white or dark brown on basal half, except for slightly paler subbasal patch, narrowly black at apex; mid tarsus dark brown to black on first and fifth tarsomeres, second and third dark brown fading to off white, fourth white. Hind leg with metallic blue coxa, shiny black or dark brown trochanter, trochantellus and femur; inner apex of hind trochantellus off-white, base of femur narrowly whitish to brown; hind tibia black or brown with narrow white annulus sub-basally, but uniformly black or brown dorsally; hind tarsus dark brown to black on first, basal 


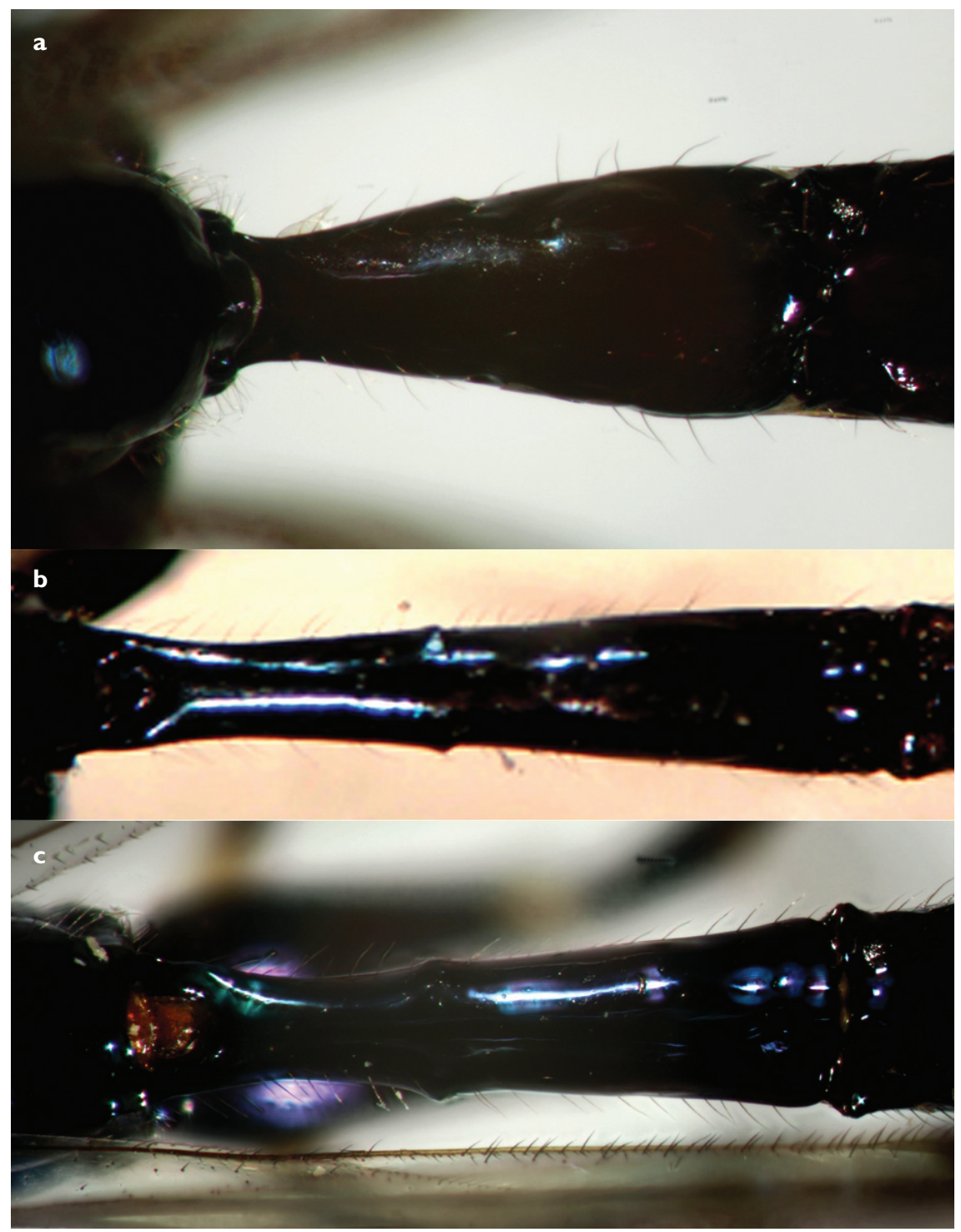

Figure 5. First tergite of male metasoma of $\mathbf{a} U$. caerulea $(\mathrm{BMNH}) \mathbf{b} U$. caerulea $(\mathrm{IAVH}) \mathbf{c} U$. giacometti; anterior to the right.

0.7 of second and apical $0.2-0.5$ of fifth tarsomeres, remainder white. Metasoma with first to fifth or sixth tergites metallic blue, fading to dark brown or near black, apical tergites dark brown to shiny black; first sternite with sclerotized part metallic blue, sclerotized sections of other sternites shiny black to brown, membranous parts of sternites white.

Variation. The male in USNM/ZMUT is smaller than the two males in BMNH and is more extensively white on the antennal flagellomeres and mid tibia. 


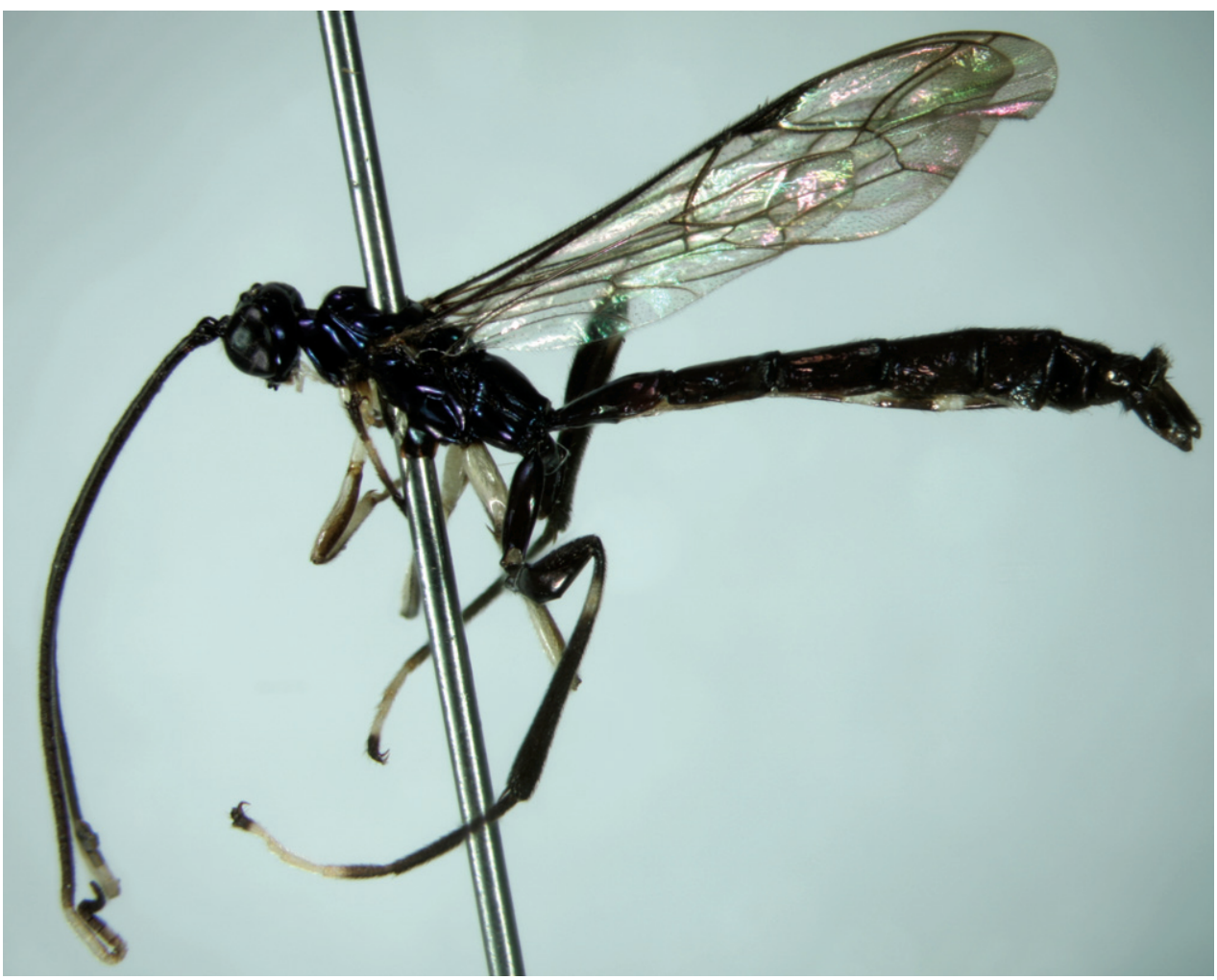

Figure 6. Paratype male of $U$. caerulea.

Biology. No specimens of Umanella have been reared but the holotype and three paratypes $(\mathrm{BMNH})$ were collected whilst flying around a standing, dead tree trunk. The hosts may be large coleopteran larvae. The ovipositor shape is rather similar to that of Dolichomitus species, which are parasitoids of beetle larvae in dead wood. Three specimens have been found at fairly high $(1,100 \mathrm{~m})$ altitude whilst one male was collected by canopy fogging at fairly low $(216 \mathrm{~m})$ altitude. In this respect the new species resembles Umanella caerulea, which also inhabits tropical forests of various altitudes (Gauld et al., 1998).

Distribution. Only known from Ecuador.

Material examined. Holotype female: 'Ecuador, Morona- Santiago, Cord. de Cutucu 6km.e. of Macas 1,100m 30.V.1981 M. Cooper' (BMNH). Paratypes: one female, same data as holotype except 26.VI.1981, one male with same data except 4.V.1981 (BMNH), one male with same data except 26.VI.1981, one male, Ecuador, Orellana, Reserva Etnica Waorani, Onkone Gare Camp, 216.3 m, 21.VI.1994, $00^{\circ} 39^{\prime} 25.7^{\prime \prime} \mathrm{S}, 076^{\circ} 27^{\prime} 10.8^{\prime \prime} \mathrm{W}$, fogging, terra firme forest, T.L.Erwin et al. leg. (held in trust for Ecuador at NMNH, but currently on loan to ZMUT).

Etymology. We are pleased to give the name suggested by Mrs Jean Halperin, who won a competition to name this beautiful species in celebration of the opening of the Natural History Museum's Darwin Centre Two, where the holotype is housed. The 


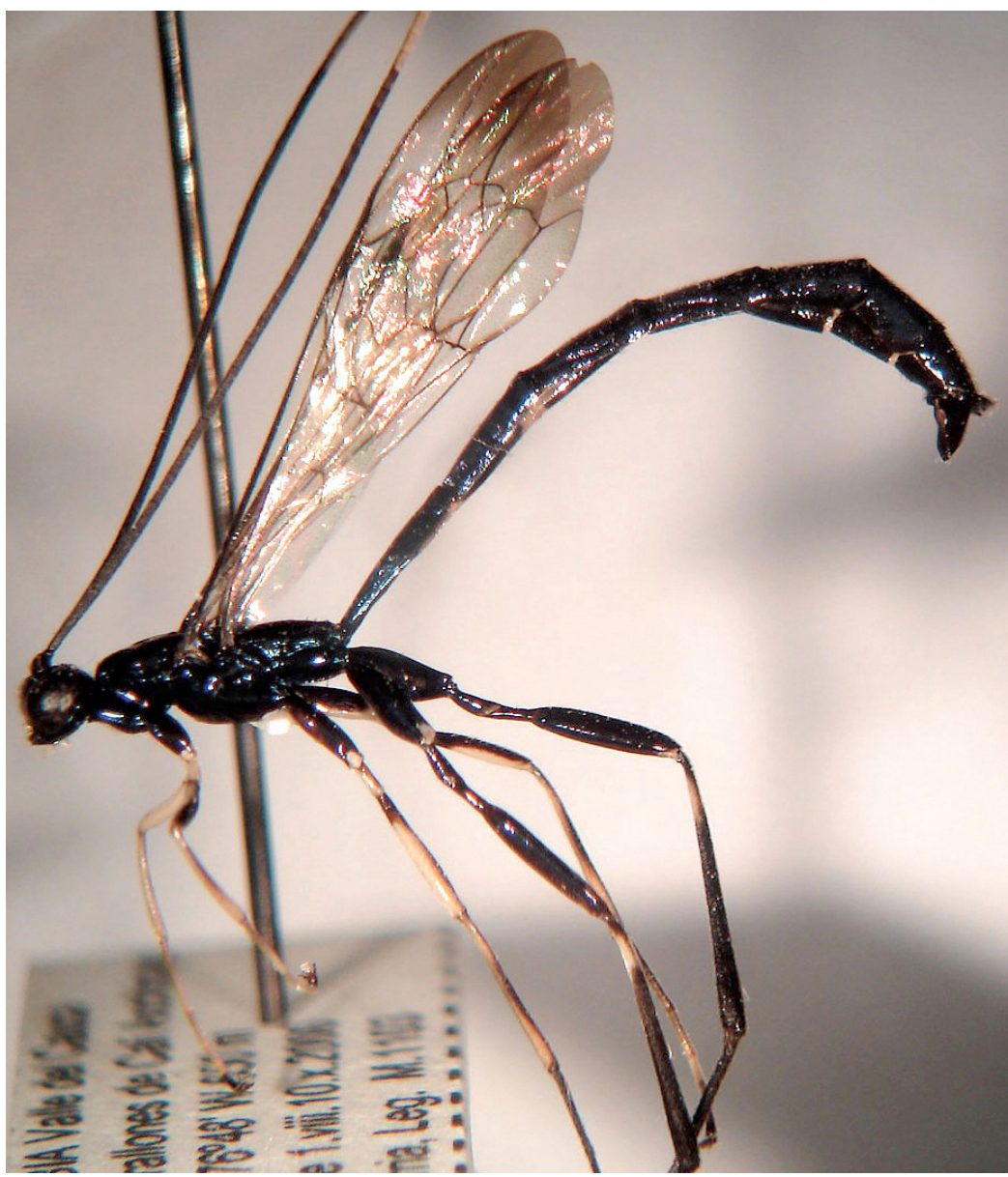

Figure 7. Male of U. caerulea, Colombia (IAVH).

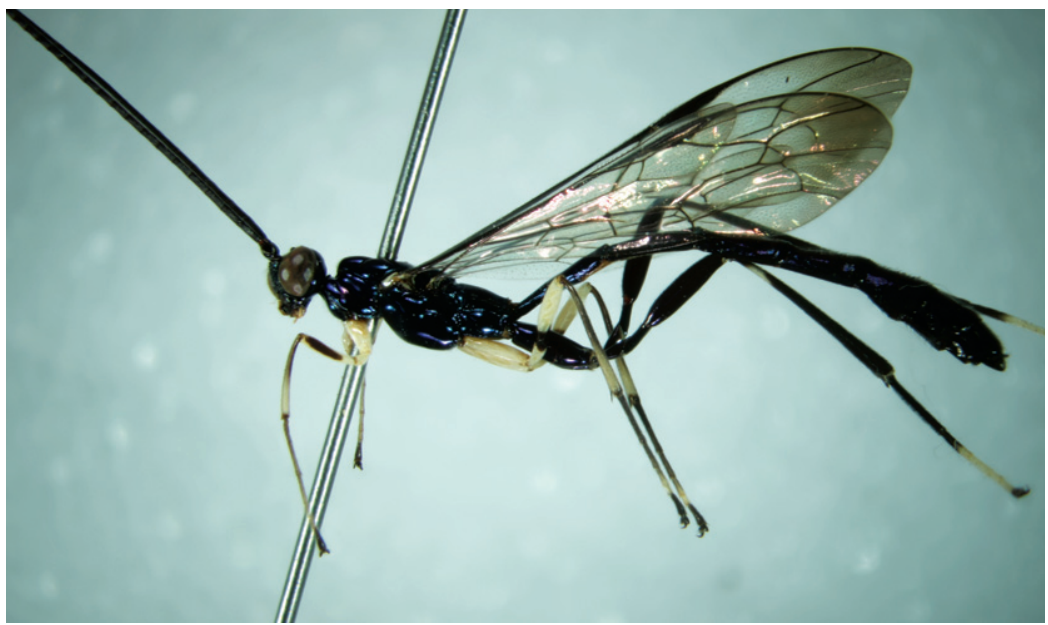

Figure 8. Paratype male of $U$. giacometti (BMNH). 


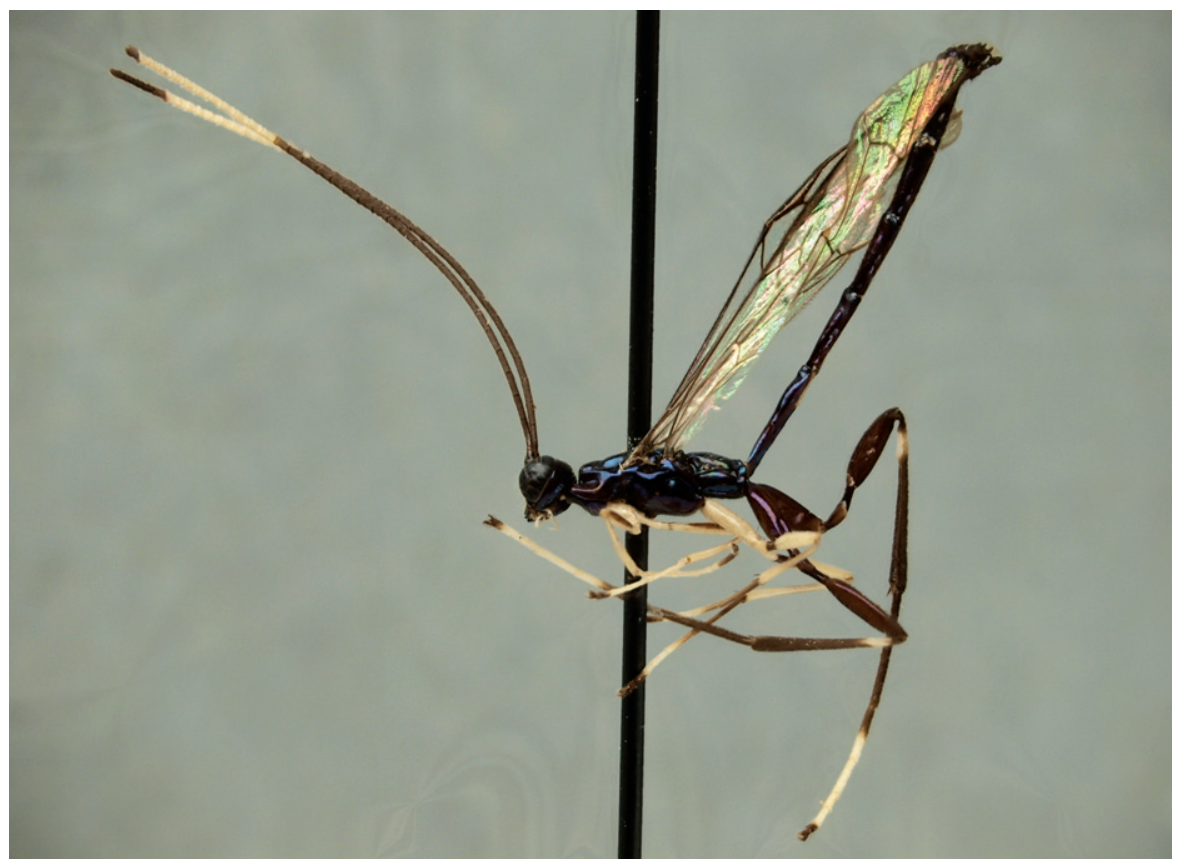

Figure 9. Paratype male of $U$. giacometti (ZMUT/USNM).

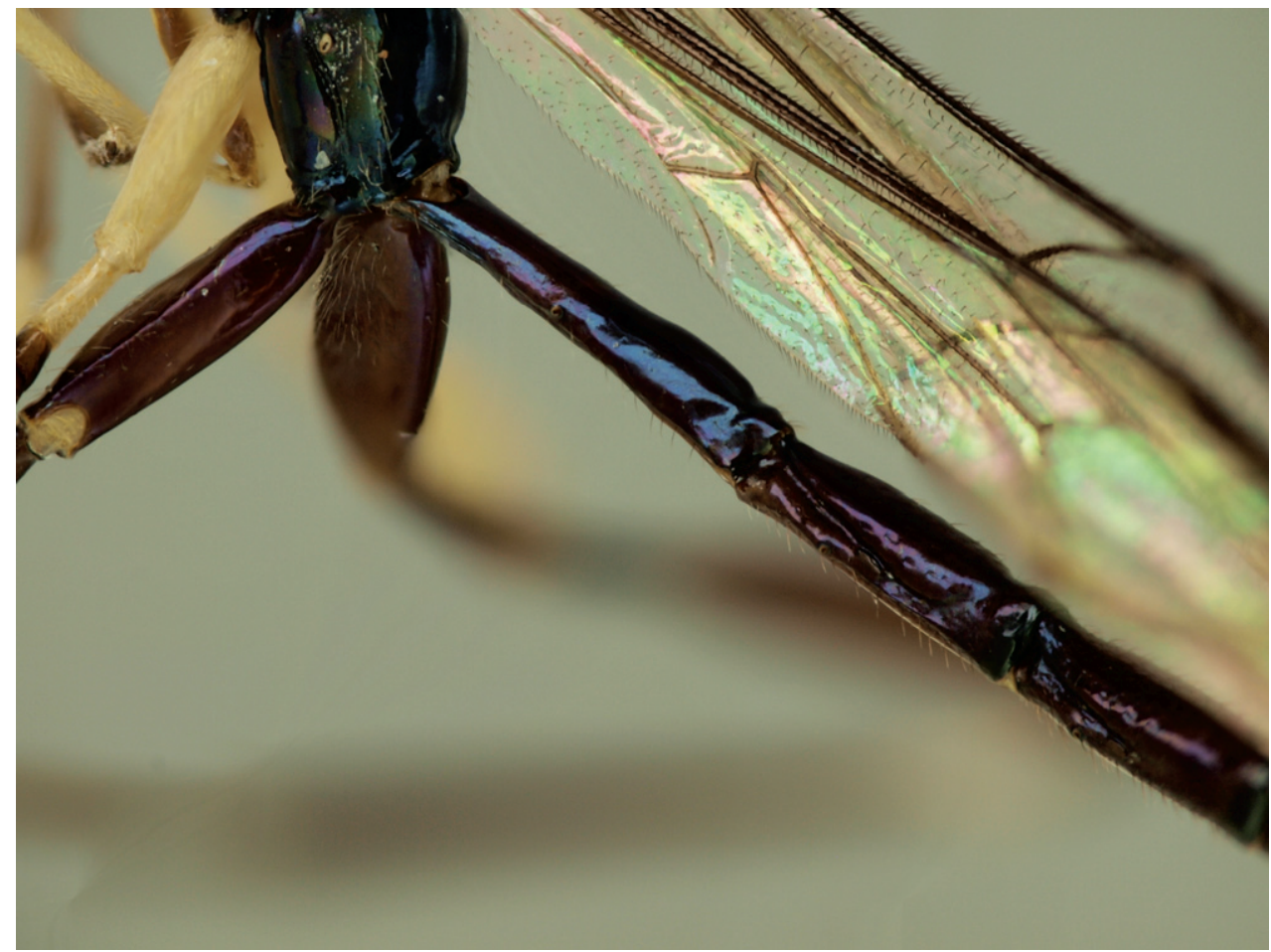

Figure 10. Paratype male of U. giacometti (ZMUT/USNM), first and second tergites. 
name refers to the wasp's resemblance to the slender, attenuated figures of the Swiss artist, Alberto Giacometti and is a noun in apposition.

\section{Acknowledgments}

We are grateful to Harry Taylor, of the Natural History Museum photo unit, for taking superb photographs of the holotype of $U$. giacometti. Dr Vladimir Blagoderov helped with other photography and image stacking. We are indebted to Martin Cooper for collecting four of the type series of $U$. giacometti, and so many other interesting $\mathrm{Hy}$ menoptera, and donating them to the Natural History Museum, and to Dr. Terry L. Erwin for providing us with his interesting canopy fogging samples which yielded one male of the type series of $U$. giacometti. We are grateful to MSc Anu Veijalainen for her help in sorting the canopy fogging samples. Umanella specimens in IAVH were collected thanks to the support of NSF grant DEB 0205982 to M.J. Sharkey and B.V. Bryan. Claudia Alejandra Medina from IAVH kindly provided access to specimens under her care. And thank you to Jean Halperin for suggesting the species name, giacometti.

\section{References}

Gauld ID (1991) The Ichneumonidae of Costa Rica, 1. Memoirs of the American Entomological Institute 47: 1-589.

Gauld ID, Ugalde Gómez JA, Hanson P (1998) Guía de los Pimplinae de Costa Rica. Revista de Biologia Tropical 46 Supplement 1:1-189. 